\title{
Root Cultures: In vitro Conservative Method for Metabolite Extraction from $A$. paniculata
}

\author{
Arpita Mahobia* and Zenu Jha \\ Department of Plant Molecular Biology and Biotechnology, Indira Gandhi Krishi \\ Vishwavidyalaya, Raipur (C.G.) 492012, India \\ *Corresponding author
}

\begin{abstract}
A B S T R A C T
Medicinal plants are a significant part of medicine systems due to pharmaceutically important secondary metabolites produced. Wild collection is the source to fulfil the increasing demand of these compounds which make plant species vulnerable. So, conservation of species is very essential along with the harvesting of medicinal plants. Here, root cultures of medicinal plants under in vitro condition may provide a source of secondary metabolite without affecting the natural population. The root cultures accompanied with the agroinfection with Agrobacterium rhizogenes may provide a cost effective way to produce roots for secondary metabolite production. A. paniculata is a source of andrographolide which have several medicinal properties. This research targeted towards the development of a conservative process for commercial production of andrographolide with the development of hairy root cultures in large scale and elicitation of andrographolide along with the isolation of pure andrographolide from hairy root cultures. The results of the work included highest $62.83+1.69 \%$ hairy root induction percentage in 10.2 induction days when apical meristem co-cultivated with Agrobacterium rhizogenes (MTCC 532) in half strength MS supplemented with acetosyringone $400 \mu \mathrm{M}$. The best media for mass multiplication was found to be semi solid media with 40.8 fold increase in total biomass yield (fresh weight) after six weeks of culturing. Among different elicitation treatments given, highest andrographolide content $(4695.9 \mu \mathrm{g} / \mathrm{gm} \mathrm{DW})$ with 3.0 fold increase compared to control was obtained when hairy root cultures were exposed to $50^{\circ} \mathrm{C}$ temperature for one hour. This technique will give biomass yield of $6.81 \mathrm{gm} / \mathrm{L}$ (dry weight) which will produce $32000 \mu \mathrm{g} / 6.81 \mathrm{gm} \mathrm{DW}$ andrographolide. The isolation of pure andrographolide crystals from hairy root cultures have been done which can be used further for screening and utilization in pharmaceutical industries after screening in animal models.
\end{abstract}

Keywords

Root cultures, $A$. paniculata, Andrographolide, Hairy roots, etc.

Article Info

Accepted:

20 February 2018

Available Online:

10 March 2018

\section{Introduction}

Plants have been used as a source of medicine for thousands of years all over the world throughout human history. They produce secondary metabolites which have specific properties. These metabolites are consumed as a herb extract in traditional medicine or in purified form in modern medicine. There is an increase in demand for medicinal plants but over collection has resulted many species under threat to become extinct. So, an 
alternative method is needed to have a continuous supply of these compounds without affecting the natural population. Here biotechnological approaches can have answer to this problem. Root cultures are the production of roots without the formation of whole plant using limited supply of mother plant. Root cultures technique with the use of growth hormones is one way to get surplus amount of roots in vitro independent of season and climate in limited time. The other way to get roots in large scale within lesser time is through the use of hairy root culture technology.

A. paniculata (Andrographis paniculata) is a medicinal herb which is used as an antimicrobial (Radhika et al., 2008), antidiabetic, anti-cancer (Maiti et al., 2010) and hepatoprotective agent. Its properties are attributed to andrographolide which is a diterpene lactone. It is present in very low quantity in roots $(1500 \mu \mathrm{g} / \mathrm{gm}$ DW) (Marwani et al., 2015). In Indian market, its dry herb extract costs Rs. $1000-1500$ per $\mathrm{kg}$ and $98 \%$ pure andrographolide costs Rs. 4106.59/100 $\mathrm{mg}$. Its demand is met through wild collection resulting in approximately $39 \%$ of population reduction and it has been identified under vulnerable (VU) species category in Chhattisgarh state (Ved et al., 2014). So, there is a need of alternative to meet the industrial demands. Therefore, the present study aimed towards the selection of best medium for higher hairy root induction and mass multiplication as well was to enhance the andrographolide content by elicitation through utilizing biosynthetic pathways.

\section{Materials and Methods}

\section{Experimental materials}

Apical meristem of $1-1.5 \mathrm{~cm}$ length was collected as explant from 2-3 month old healthy plant of well evaluated genotype grown and maintained at green house, Department of Plant Molecular Biology and Biotechnology, College of Agriculture, Indira Gandhi Krishi Vishwavidyalaya, Raipur. Agrobacterium rhizogenes (MTCC 532) obtained from Indian microbial technology (IMTECH), Chandigarh was used for agroinfection. For infection of explant, bacterial suspension was prepared using a single loop of bacterium inoculated on $20 \mathrm{ml}$ Nutrient Agar medium (NAM) broth and incubated in dark at $25+1^{\circ} \mathrm{C}$, on a rotary shaker at 120 revolutions per minute for $4-5$ hours, until optical density of culture reaches $\mathrm{OD}_{600}=0.6$. Four different elicitors were used for elicitation of andrographolide (heat and cold based elicitor, jasmonic acid induced elicitor and sodium chloride).

\section{Method}

\section{Hairy root induction}

Apical meristem explant was sterilized using bavistin $1 \%(\mathrm{w} / \mathrm{v})$ and $0.1 \%(\mathrm{w} / \mathrm{v})$ Mercuric chloride $\left(\mathrm{HgCl}_{2}\right)$ for 1-2 minutes and 60s respectively followed by 2-3 times rinse in sterilized distilled water to remove traces of bavistin and $\mathrm{HgCl}_{2}$. The sterilized explants were shaked in bacterial suspension for 5 minutes after pricking with sterile needle dipped in suspension.

Afterwards, the infected explants were cocultivated on Murashige \& Skoog agar medium with different combinations of NAA and acetosyringone incubated in dark at $25+1^{0} \mathrm{C}$ for 48 hours. After co-cultivation, each explant was washed with $250 \mathrm{mg} / \mathrm{L}$ cefotaxime to eliminate Agrobacterium.

Then explants were inoculated in MS media supplemented with cefotaxime to check bacterial growth. Then, after one week of hairy root induction, they were subjected to hairy root mass multiplication. 


\section{Confirmation of transformation event}

Confirmation of the presence of hairy roots was done on the basis of morphological characters (Karmarkar et al., 2001) and molecular confirmation of hairy roots was carried out using rolC gene specific primers. Amplified products were visualized under Gel documentation system after running the samples on $1.2 \%$ agarose gel.

\section{Mass multiplication of hairy roots}

Hairy roots of approximately $2 \mathrm{~cm}$ size and 0.015 to $0.020 \mathrm{~g}$ fresh weight were subjected to mass multiplication media for its increased growth. Two types of media, liquid and semisolid media were used. Biomass estimation of fresh roots was done by calculating the growth index of the best growing hairy root clone (Verma et al., 2002).

\section{Elicitation of andrographolide in hairy roots}

Elicitation of andrographolide was done after six weeks of culturing using physical stress (High and low temperatures) and chemical stress using jasmonic acid and sodium chloride.

High and low temperature stress was given with various exposure times. Similarly, hairy root cultures were subjected to treatment with jasmonic acid $(75,100$ and $125 \mu \mathrm{M})$ and sodium chloride at concentration 50,70 and $90 \mathrm{mM}$. The estimation of andrographolide was done using HPLC (High performance liquid chromatography).

\section{Isolation of andrographolide from hairy roots}

After elicitation, the hairy roots were subjected to isolation of pure andrographolide crystals and its purity was tested.

\section{Statistical analysis}

All numerical data were statistically analyzed by ANOVA. The Factorial Completely Randomized Design was used to compare means at $5 \%$ significance level.

\section{Observations and Results}

\section{Hairy root induction}

Acetosyringone concentrations $(0,200,300$, 400 and $500 \mu \mathrm{M})$ with NAA $(0,0.5,0.75$ and 1 $\mathrm{mg} / \mathrm{L}$ ) were selected for hairy root induction. The aim of selection of these treatment combinations was to find out the effect of acetosyringone and NAA individually as well as its interaction effect on hairy root induction. It was found that the average root induction percentage varied from 2.96 to $62.83 \%$ in different treatment combinations of NAA and acetosyringone (Fig. 1). Out of all the treatments, the treatment with acetosyringone $400 \mu \mathrm{M}$ without NAA (C12) was observed with maximum $62.833+1.69 \%$ average hairy root induction percentage followed by $52.597+1.87 \%$ in acetosyringone $400 \mu \mathrm{M}$ and NAA $0.5 \mathrm{mg} / \mathrm{L}$ (C11) (Fig. 2). Analysis of two factor completely randomized design shows significant difference between treatments. The response of explant towards the individual effect of acetosyringone and NAA shows that acetosyringone with $400 \mu \mathrm{M}$ concentration was best with $52.705 \%$ average hairy root induction and effect of NAA on average root induction was higher in control with zero NAA $(35.142 \%)$ as the presence of NAA induces the formation of adventitious roots (Fig. 3). It has also been observed that hairy root induction was increased to 21 folds as compared to control. The effect of the treatments on average hairy root induction time ranged from 8.3 to 39 days. It has been observed that the treatment $\mathrm{C} 1$ with $200 \mu \mathrm{M}$ acetosyringone and $1 \mathrm{mg} / \mathrm{L}$ NAA showed lowest time (8.3 days) for hairy root induction. 
An increase in root induction time was observed when NAA concentration was decreased from 1 to $0.5 \mathrm{mg} / \mathrm{L}$ but when NAA concentration reduced to $0 \mathrm{mg} / \mathrm{L}$, the root induction time decreased. This indicates that NAA results in checking the growth of hairy roots and increases the possibility of formation of adventitious roots. The results obtained from the effect of co-cultivation media on hairy root induction was found similar with the effect of NAA on hairy root induction in Mucuna prureins (Vishwakarma et al., 2017). The increase in transformation frequency (hairy root induction) by acetosyringone in our studies could be attributed to its ability to active vir genes. Acetosyringone mediated activation of vir genes has been known to enhance transformation(Gelvin, 2000).

\section{Confirmation of transformation}

The morphological confirmation was done on the basis of specific characteristics which are unique to hairy roots. The first character is the emergence of roots from pricked part of explant. The second character is profuse lateral branching, due to which biomass increased and consequent increase in the number of elongating tips occurred. The third important character is root shows negative geotropism (Fig. 4).

It is a common phenomenon in the roots transformed with A. rhizogenes (Karmarkar et al., 2001).

Molecular confirmation was done to confirm the presence of Ri T-DNA in hairy roots of $A$. paniculata. DNA amplified with rolC gene specific primer was separated on agarose gel $1.2 \%$ and visualized in gel documentation system showed the presence of the fragment with length $1000 \mathrm{bp}$ in hairy root which corresponds to rolC genes from Ri plasmid of MTCC 532 but not found in untransformed roots (Mahobia et al., 2015) (Fig. 5). This indicated that rolC genes from Ri plasmids of $R$. rhizogenes strain MTCC 532 were integrated in $A$. paniculata hairy roots (Kovalenko et al., 2003, Shi et al., 2003).

\section{Mass multiplication of hairy roots}

For mass multiplication of hairy roots, the liquid media and semi-solid media were tested for increased biomass. It was found that the hairy roots survived with $63.33 \%$ survivability with 19.32 fold increase in total biomass yield (Fresh weight) in liquid media (Fig. 6) whereas the hairy roots inoculated in semisolid media responded with highest average increase in biomass yield (40.85) with $83.3 \%$ survival percentage which is almost the double of the growth index observed in liquid media (19.32).

Statistical significance testing using single factor completely randomized design revealed that treatments were having significant difference among each other at $5 \%$ level of significance. This clearly indicates that semisolid media was the best for mass multiplication of hairy roots of $A$. paniculata.

\section{Elicitation of andrographolide}

Elicitation of andrographolide is important because of associated pharmaceutical properties and great economic value. Elicitation is principally giving stress to cell whose results in general includes reduced biomass but increase in secondary metabolite content. Response of hairy root cultures with stress varies on the type of elicitor used.

The main target of this research was to get andrographolide yield in large amount in cost effective manner. After six weeks of culturing, the multiplied hairy roots were used for elicitation. Four different elicitation treatments were given. Every elicitor responded differently in physical and chemical stress. 

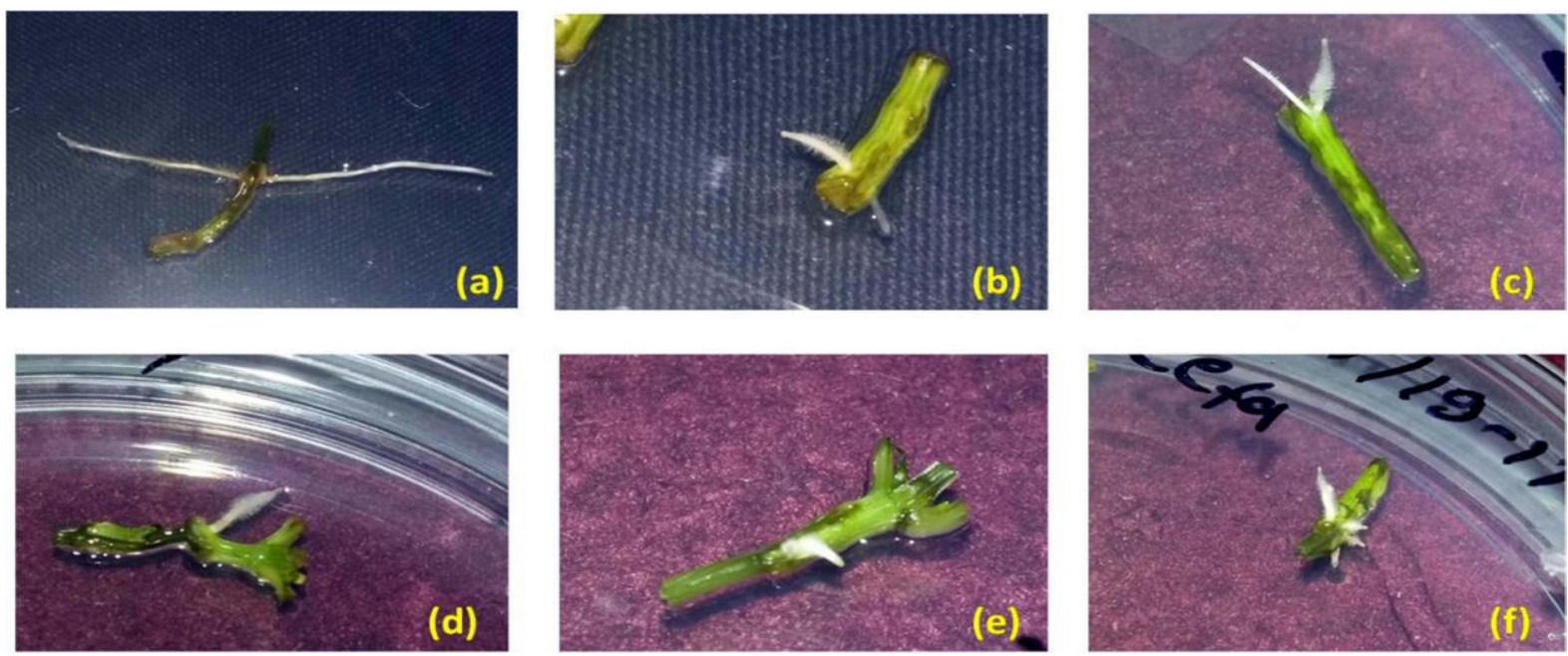

Figure 1(a)-(f) - Apical meristem explants with hairy root induction

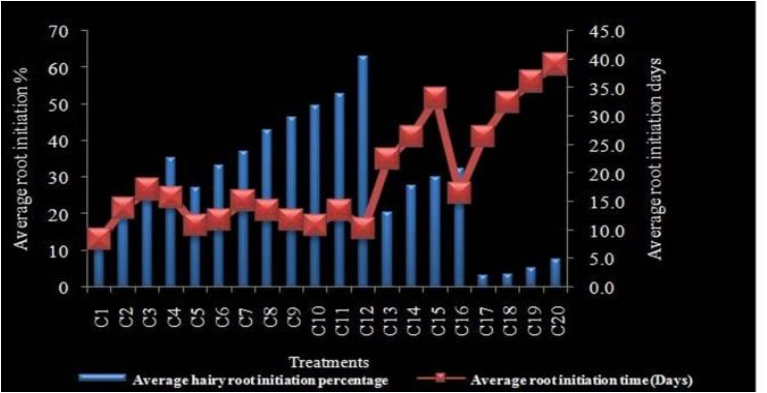

Figure 2 :- Graph showing effect of treatment combination of acetosyringone and NAA on hairy root induction and induction time (days)

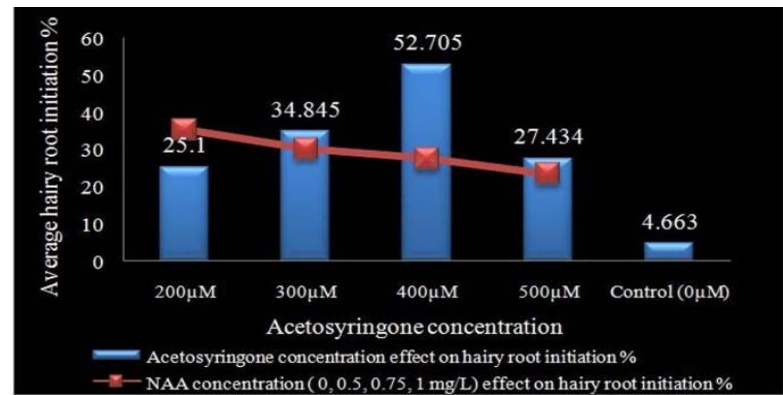

Figure 3 :- Graph showing individual effect of acetosyringone and NAA on hairy root induction
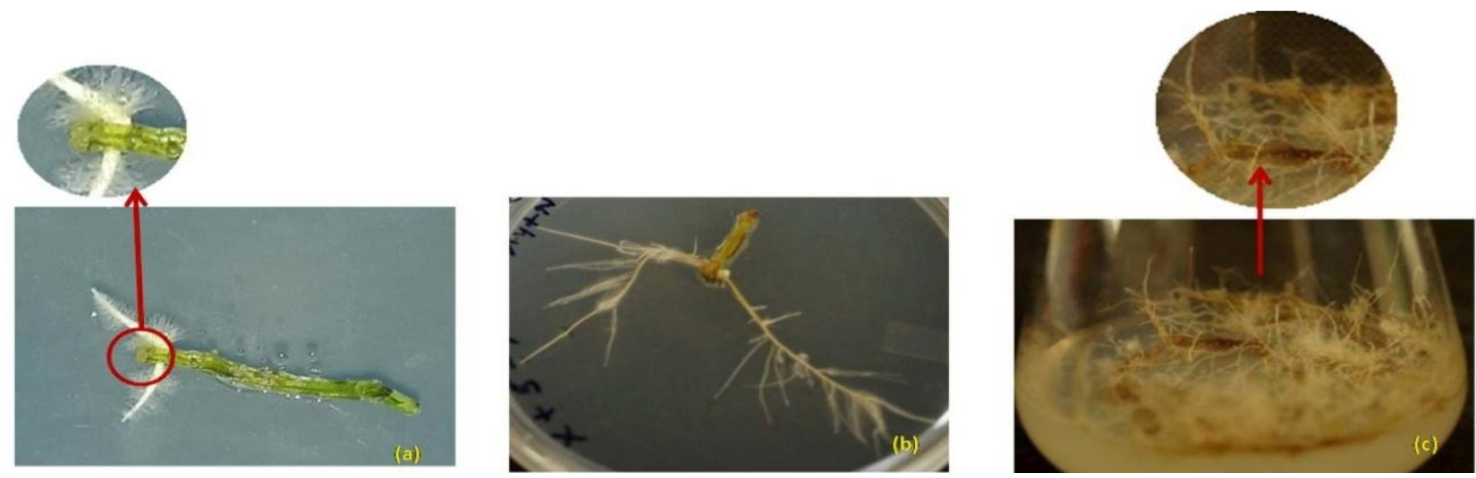

Figure 4 :- Morphological confirmation of hairy roots (a) emergence from pricked part, (b) Presence of lateral roots and (c) roots showing negative geotropism

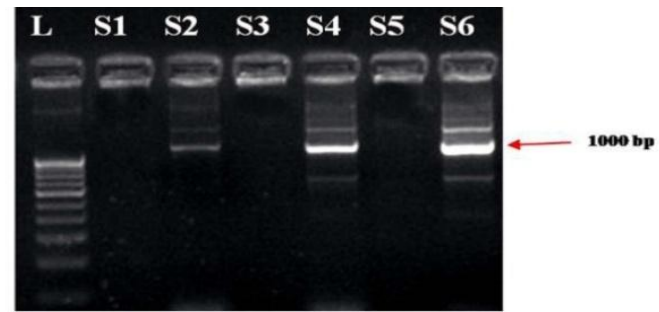

Figure 5: PCR amplification of DNA extracted from different tissues using rolC gene specific primer: L ladder 100 bp; S1- Non-transformed roots; S2 - transformed roots; S3-Leaf, S4--transformed roots; S5Adventitious roots; S6 Plasmid (Positive control) 

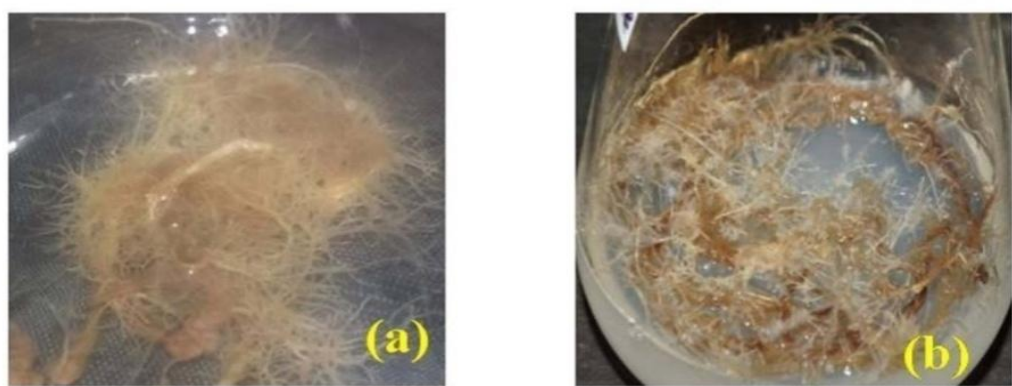

Figure 6:- Hairy roots in (a) liquid media and (b)solid media

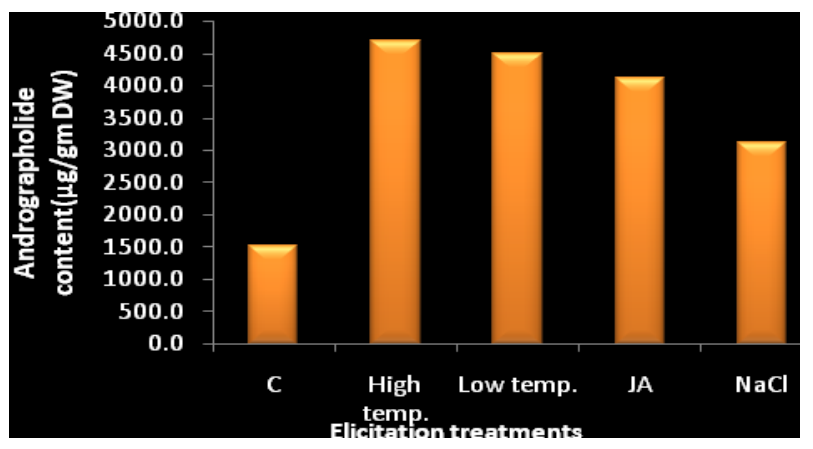

Figure 7: Effect of elicitation treatments on andrographolide yield

Fig.8 HPLC chromatogram (a) Standard andrographolide, (b) Control roots, (c) Treated hairy roots- 50 degree, 60 minutes

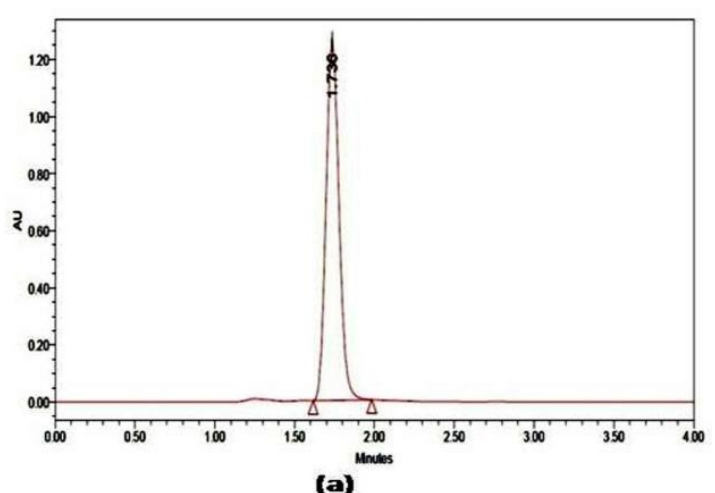

(a)
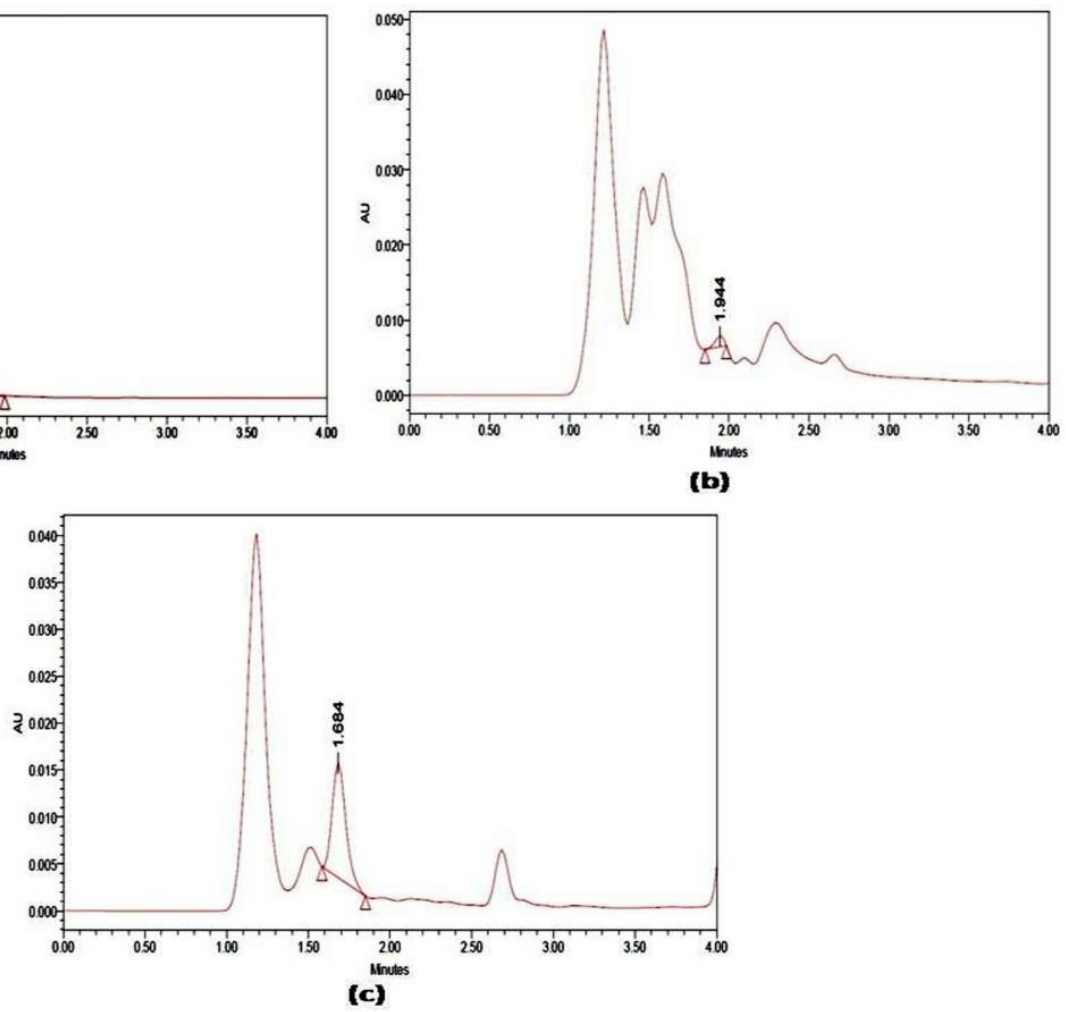

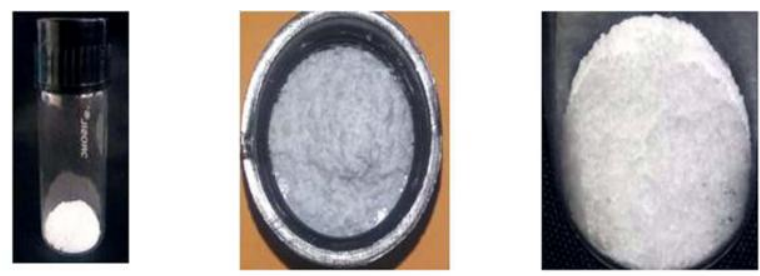

Figure 9 : Isolated andrographolide crystals

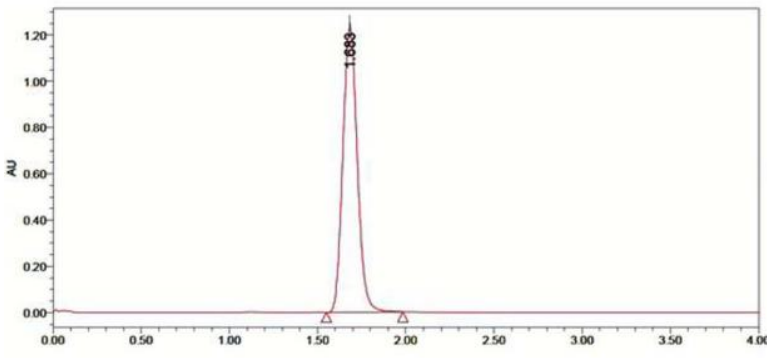

(a)

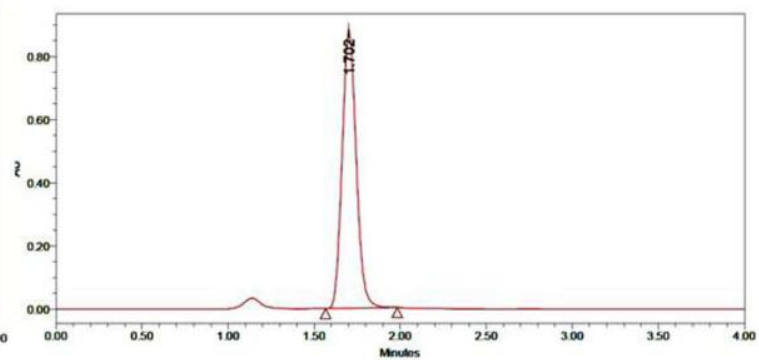

(b)

Figure 10 : HPLC chromatogram (a) Standard andrographolide and (b) Isolated andrographolide

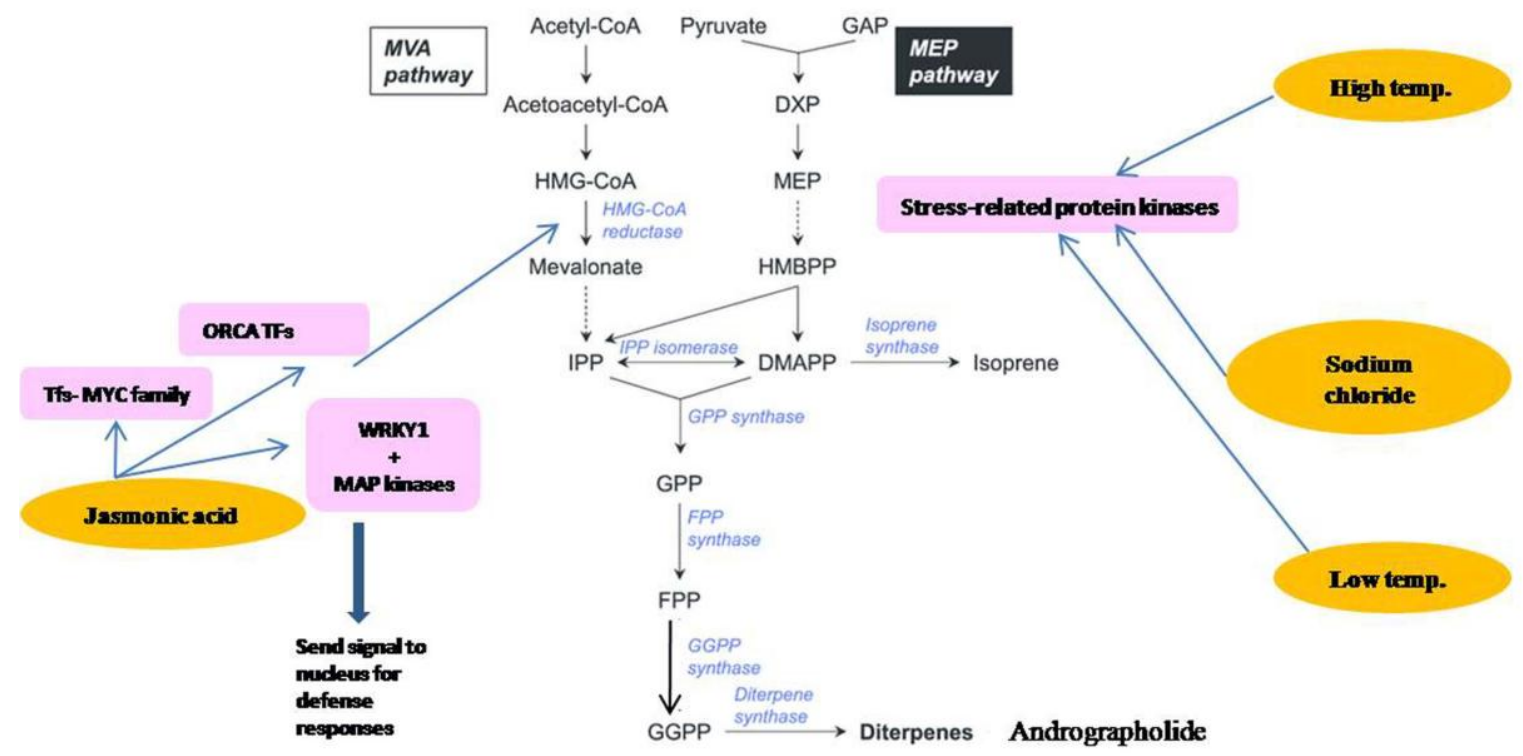

Figure 11: Response to different elicitor on biosynthesis of andrographolide

Among the treatments given for high temperature stress, the maximum andrographolide content, $4695.9 \mu \mathrm{g} / \mathrm{gm} \mathrm{DW}$ was observed when hairy roots exposed with $50^{\circ} \mathrm{C}$ temperature at 60 minutes of exposure time with 3.0 fold increase compared to control.
These similar findings has been reported in leaf and stem system of normal regenerated plant. The exposure to higher temperatures has been shown to affect the efflux of pigment from Beta vulgaris hairy roots (Thimmaraju et al., 2003). It can also be depicted that as temperature 
increased from $25^{\circ} \mathrm{C}$ to $50^{\circ} \mathrm{C}$, the andrographolide content decreases initially then sudden rise in content was observed with increased temperature. It is also reported that low temperature 12 and $18^{\circ} \mathrm{C}$ increased eleutheroside accumulation in somatic embryos (Mohammad et al., 2006).

The overall result of treatment with four types of elicitors revealed that high temperature treatment of $50^{\circ} \mathrm{C}$ temperature for 1 hour should be used to elicit andrographolide in hairy root cultures (Fig.8). The statistical analysis of all the elicitation treatments having maximum andrographolide content was done using completely randomized design which resulted in significant results among the treatments and showed that at $5 \%$ level of significance the untreated hairy roots show significant difference in andrographolide content than normally regenerated roots. The results also revealed non-significant results among the three treatments of jasmonic acid, high temperature at 50 degrees and low temperature at 0 degrees which indicates the use of any of the treatments for elicitation on the basis of convenience and cost. Also, high temperature treatment was found significant over treatment without sodium chloride for 48 hours (Fig. 7). This indicates that 50 degree temperature exposure for 1 hour to the hairy roots will produce maximum andrographolide compared to the untreated hairy roots.

High temperatures, low temperatures and high salt concentration activates the stress related protein kinases which sends the signal to nucleus for defense related activation of genes which are involoved in biosynthesis of secondary metabolites (Fig. 11). The signalling pathway of jasmonic acid is well studied which suggests the formation of a number of transcription factors which in association or individually triggers the protein kinases to send signal for biosynthesis. These transcription factors also triggers the HMG-CoA reductase enzyme for biosynthesis of andrographolide (Krasensky et al., 2012).
For obtaining maximum hairy root biomass of A.paniculata under in vitro condition, we recommend to use apical meristem as explant in co-cultivation media of half strength MS supplemented with acetosyringone $400 \mu \mathrm{M}$ for co-cultivation with MTCC 532 strain of $A$. rhizogenes for high hairy root induction. For higher biomass production, semi solid media (Half strength MS with $3 \%$ sucrose, cefotaxime $250 \mathrm{mg} / \mathrm{L}$ and agar $0.8 \%$ with gradual decrease in cefotaxime 125 and $0 \mathrm{mg} / \mathrm{L}$ and agar agar with 0.7 and $0.55 \%$ respectively) should be used followed by exposing roots to $50^{\circ} \mathrm{C}$ temperature for one hour. This will give biomass yield of $6.81 \mathrm{gm} / \mathrm{L}$ (dry weight) which will produce $32000 \mu \mathrm{g} / 6.81 \quad \mathrm{gm}$ DW andrographolide.

\section{Isolation of andrographolide from hairy roots}

The andrographolide crystals were isolated from hairy roots (Fig. 9) and andrographolide content of the isolated crystals was tested for purity (Fig. 10). The further screening of crystal is required for its utilization in pharmaceutical industries. This technique will create a sustainable approach for the extraction of andrographolide without affecting the natural population of the mother plant.

\section{Acknowledgement}

We acknowledge the fund provided by Indira Gandhi Krishi Vishwavidyalaya and Chhattisgarh Council of Science and Technology for carrying out this research work and the Department of Plant Molecular Biology and Biotechnology, College of Agriculture, Raipur for providing lab facilities.

\section{References}

Gelvin SB (2000) Agrobacterium and plant genes involved in T-DNA transfer and integration. Annual review of plant biology 51(1): 223-256.

Karmarkar SH, Keshavachandran R (2001) Genetic transformation and hairy root induction in Holostemma ada-kodien $\mathrm{K}$. 
Schum-a vulnerable medicinal plant. NISCAIR-CSIR, India.

Kovalenko P G, Maliuta S S (2003). An effect of transformation by $\mathrm{Ri}$ plasmids and elicitors on licorice cells and secondary metabolite production. Ukrainica Bioorganica Acta 1(1): 50-60.

Krasensky Julia, Jonak Claudia (2012) Drought, salt, and temperature stress-induced metabolic rearrangements and regulatory networks. J Exp Bot 63 (4): 1593-1608

Mahobia A, Jha Z (2015) Efficiency of Method and Media Composition on Transformation of Andrographis paniculata for Hairy Root Production. Journal of Cell and Tissue Research 15(1): 4897-4902

Maiti K, Mukherjee K, Murugan V, Padasaha B, Mukherjee PK (2010) Enhacing bioavailability and hepatoprotective activity of andrographolide from Andrographis paniculata, a well-known medicinal food, through its herbosome. Journal of Science Food Agriculture 90: 43-51.

Marwani Erly, Pratiwi Dian, Wardhani Karlina, Esyanti Rizkita (2015) Development of Hairy Root Culture of Andrographis paniculata for in vitro Andrographollide Production. Journal of Medical and Bioengineering 4 (6): 446-450

Mohammad Abdullah Shohael, Mohammad Babar Ali, Yu Kee-Won, Hahn Eun-Joo, Paek Kee-Yoeup (2006) Effect of temperature on secondary metabolites production and antioxidant enzyme activities in Eleutherococcus senticosus somatic embryos. Plant Cell Tiss Organ Cult 85: 219-228

Radhika P, Sastry BS, Madhu HB (2008) Antimicrobial screening of Andrographis paniculata (Acanthaceae) root extracts. Research Journal of Biotechnology 3(3): 62-63.

Shi HP, Kintzios S (2003) Genetic transformation of Pueraria phaseoloides with Agrobacterium rhizogenes and puerarin production in hairy roots. Plant Cell Rep. 21: 1103-1107.

Thimmaraju R, Bhagyalakshmi N, Narayan MS, Ravishankar GA (2003) Kinetics of pigment release from hairy root cultures of Beta vulgaris under the influence of $\mathrm{pH}$, sonication, temperature and oxygen stress. Process Biochemistry. Elsevier, 38(7):1069-1076.

Ved DK, Suma TS, Srinivas Vijay, K Harish, Rani Sugandhi, Bhat Surekha, Sumanth MV, Nikhil Desale (2014) ENVIS Newsletter on Medicinal Plants. 7(1, 2, 3 \&4): $1-16$

Verma Praveen C, Singh Digvijay, Rahman Laiq ur, Gupta Madan Mohan, Banerjee Suchitra (2002) In vitro-studies in Plumbago zeylanica: rapid micropropagation and establishment of higher plumbagin yielding hairy root cultures. J. Plant Physiol. 159: 547-552

Vishwakarma KS, Mohammed SI, Chaudhari AR, Salunkhe NS, Maheshwari VL (2017) Micropropagation and Agrobacterium rhixogenes mediated transformation studies in Mucuna pruriens (L.) DC. Indian J. Nat Prod Resour. 8(2): 172-178.

\section{How to cite this article:}

Arpita Mahobia and Zenu Jha. 2018. Root Cultures: In vitro Conservative Method for Metabolite Extraction from A. paniculata. Int.J.Curr.Microbiol.App.Sci. 7(03): 2442-2450. doi: https://doi.org/10.20546/ijcmas.2018.703.285 